outer bud scale stretches considerably after expulsion of the sprout. The first cataphyll is lifted up by the sprout and remains green for some time.

The observations on $S$. acmophylla were made on a single plant received from the Botanic Garden of Cairo. Studies should be extended to other specimens from different natural habitats and to other species of the Humboldtianae e.g. S. subserrata Willd.

\title{
References
}

Chmelar̆, 1978. Taxonomic importance of bud scales in the Salix genus. Folia dendrologica $4 / 78$.

Kimura Ch. \& Sugaya A. 1965. Some observations on the axillary buds of two pleiandrous willows, Salix bonplandiana and Salix safsaf. Ecological Review 16, 201-6.

\section{Resistance of Salix viminalis to gall-midge attack}

\section{Carolyn Glynn and S. Larsson}

Department of Plant and Forest Protection, SLU Box 7044, S-75067, Uppsala, Sweden

We are interested in understanding why certain clones of basket willow Salix viminalis $\mathrm{L}$. are resistant to attack by the gall-midge Rabdophaga marginemtorquens Bremi. That this resistance is of a genetic nature is clear but which host-plant characteristics are responsible are unknown.

Results from field studies show differences in density of galls per shoot on the resistant and susceptible willow types. This resistance is affected neither by nutrient regime nor by earlier midge attack. Laboratory studies reveal that females do not discriminate between the two plant types during oviposition.

Hypotheses have been based on observations of extremely high early larval mortality rates on the resistant clones. Two explanations for this are that the larvae do not succeed in initiating feeding on the resistant clones, or commence the larvae feeding but die soon thereafter. Given that larvae do not initiate feeding we can see three possible mechanisms for this: larvae are unable to break through the cell wall of the leaf, resistant clones lack certain feeding stimulants, or they contain toxins. When larvae die soon after they commence feeding, explanations could lie in either that the plant responds actively to the midge attack with an induced defence or that the food is unsuitable for the larvae, a so called constitutive defence. 